\title{
Effect of genetic polymorphisms involved in folate metabolism on the concentration of serum folate and plasma total homocysteine (p-tHcy) in healthy subjects after short-term folic acid supplementation: a randomized, double blind, crossover study
}

\author{
Rona Cabo - Sigrunn Hernes • Audun Slettan • \\ Margaretha Haugen • Shu Ye $\cdot$ Rune Blomhoff • \\ M. Azam Mansoor
}

Received: 12 November 2014 / Accepted: 23 February 2015/Published online: 11 March 2015

(C) Springer-Verlag Berlin Heidelberg 2015

\begin{abstract}
Data on the effect of combined genetic polymorphisms, involved in folate metabolism, on the concentration of serum folate after folic acid supplementation are scarce. Therefore, we investigated the impact of seven gene polymorphisms on the concentration of serum folate and p-tHcy in healthy subjects after short-term folic acid supplementation. In a randomized, double blind, crossover study, apparently healthy subjects were given either $0.8 \mathrm{mg}$ folic acid per day $(n=46)$ or placebo $(n=45)$ for 14 days. The washout period was 14 days. Fasting blood samples were collected on day 1, 15, 30 and 45. Data on subjects on folic acid supplementation $(n=91)$ and on placebo $(n=45)$ were used for the statistical analysis. The
\end{abstract}

R. Cabo · A. Slettan $\cdot$ M. A. Mansoor $(\bowtie)$

Department of Natural Sciences, University of Agder,

Kristiansand, Norway

e-mail: mohammad.a.mansoor@uia.no

S. Hernes

Department of Nutrition, University of Agder, Kristiansand,

Norway

\section{Haugen}

Division of Environmental Medicine, Norwegian Institute of Public Health, Oslo, Norway

\section{S. Ye}

William Harvey Research Institute, Queen Mary University of London, London, UK

R. Blomhoff

Department of Nutrition, University of Oslo, Oslo, Norway

R. Blomhoff

Division of Cancer Medicine, Surgery and Transplantation, Oslo

University Hospital, Oslo, Norway concentration of serum folate increased higher in subjects with higher age $(53.5 \pm 7.0$ years $)$ than in subjects with lower age $(24.3 \pm 3.2$ years $)$ after folic acid supplementation $(p=0.006)$. The baseline concentration of serum folate in subjects with polymorphism combination, reduced folate carrier protein, RFC1-80 GA and methylenetetrahydrofolate reductase, MTHFR677 CT+TT, was lower than RFC1-80 AA and MTHFR677 CT+TT $(p=0.002)$. After folic acid supplementation, a higher increase in the concentration of serum folate was detected in subjects with polymorphism combination RFC1-80 GA and MTHFR677 CC than RFC1-80 GG and MTHFR CT+TT combination $(p<0.0001)$. The baseline concentration of plasma total homocysteine (p-tHcy) was altered by combined polymorphisms in genes associated with folate metabolism. After folic acid supplementation, in subjects with combined polymorphisms in methylenetetrahydrofolate dehydrogenase, MTHFD1-1958 and MTHFR-677 genes, the concentration of $\mathrm{p}$-tHcy was changed $(p=0.002)$. The combination of RFC1-80 and MTHFR-677 polymorphisms had a profound affect on the concentration of serum folate in healthy subjects before and after folic acid supplementation.

Keywords Short-term folic acid supplementation . Genetic polymorphisms - Serum folate and p-tHcy concentrations

\section{Introduction}

Folate deficiency increases the risk of cardiovascular diseases (CVD), certain types of cancer and possibly decline in cognitive abilities (Daly et al. 1995; Shane 2010). 
Maternal folate deficiency and genetic polymorphisms in folate metabolism have also been linked to neural tube defects (NTDs) in new born babies (Etheredge et al. 2012). An attempt to reduce the prevalence of NTDs in the USA, the fortification of wheat flour with folic acid was started in 1998 (US FDA 1996). Furthermore, folic acid supplementations have been used to reduce the concentration of plasma total homocysteine (p-tHcy) in patients with hyperhomocysteinemia, which has been associated with CVD (Finch and Joseph 2010).

Folic acid is transported in the intestinal cells by a proton-coupled folate transporter (PCFT) (Zhao et al. 2011; Yee et al. 2010). Mostly in liver, intracellular folic acid is first reduced to dihydrofolate and later to tetrahydrofolate (THF) by the enzyme dihydrofolate reductase (DHFR). The enzyme serine hydroxymethyltransferase (SHMT) converts THF into methylenetetrahydrofolate (methyleneTHF), which is reduced to 5-methyl-THF by methylenetetrahydrofolate reductase (MTHFR). Vitamin $\mathrm{B}_{12}$ and 5-methyl-THF participate in remethylation of homocysteine into methionine by methionine synthase (MTR) (Daly et al. 1995; Shane 2010). Dietary folates do not enter directly into the intestinal cells. The enzyme $\gamma$-glutamylhydrolase $(\mathrm{GH})$ removes glutamate residues from the polyglutamates and generates folate monoglutamates, which are transported in the cells by a reduced folate carrier 1 (RFC1). RFC1 mediates bidirectional movement of folates across the cell membrane; therefore, an efficient RFC1 may maintain an optimal concentration of intracellular and extracellular folates (Zhao et al. 2011; Yee et al. 2010). Intracellular folate monoglutamates are topped with glutamate to form polyglutamates by the enzyme folylpolyglutamate synthase (FPGS). The newly formed polyglutamates are trapped and stored in the cells (Daly et al. 1995; Shane 2010).

Intracellular folates are essential for the synthesis of thymidylate; the reaction is performed by the enzyme thymidylate synthase (TS). The enzyme, methylene-THFdehydrogenase1 (MTHFD1), provides 5, 10-methyleneTHF and 10-formyl-THF, which are involved in the synthesis of DNA. Folate is also involved in the conversion of serine to glycine, where serine provides one-carbon units for the folate-dependent one-carbon reactions (Daly et al. 1995; Shane 2010).

Previously, it had been reported that individual polymorphisms in MTHFR-1298A $>$ C and MTHFR-1317T $>$ C did not have any effect on the concentration of p-tHcy; however, subjects with MTHFR-677 TT had significantly higher concentrations of p-tHcy (Pereira et al. 2004; Devlin et al. 2006; Zappacosta et al. 2014; Yang et al. 2008; Anderson et al. 2013). It was also reported that folic acid intake $(150 \mu \mathrm{g} /$ day $)$ in subjects with MTHFR677 TT had a counter effect and reduced the concentration of p-tHcy
(Yang et al. 2008). Moreover, subjects with interaction between MTHFR-677 TT and RFC1-80 GG had increased concentration of p-tHcy (Devlin et al. 2006). In women, with unexplained recurrent miscarriages, $0.5 \mathrm{mg}$ folic acid supplementation caused a significant reduction in the concentration of p-tHcy; however, the effect was pronounced in women with the highest baseline concentration of p-tHcy and MTHFR-677-TT polymorphism (Nelen et al. 1998).

Most studies have reported the effect of individual polymorphisms on the concentration of p-tHcy and serum folate, besides the reported data are not consistent. Furthermore, data on the combined effect of gene polymorphisms, in folate metabolizing genes, on the concentration of serum folate and p-tHcy after folic acid supplementation are scarce (Pereira et al. 2004; Devlin et al. 2006; Zappacosta et al. 2014; Yang et al. 2008; Anderson et al. 2013; Nelen et al. 1998; DeVos et al. 2008). Therefore, in a crossover study, we assessed the combined effect of MTHFR-677C $>$ T, MTHFR-1298A $>$ C, RFC1-80G $>$ A, MTHFD1-1958G $>$ A, MTR-2756A $>$ G, DHFR-19 del and TS gene polymorphisms on the concentration of serum folate and p-tHcy after short-term folic acid supplementation in healthy subjects.

\section{Materials and methods}

\section{Study design and study population}

A randomized, double blind, crossover study.

Flow chart diagram of study participants is provided (Fig. 1). Inclusion criteria were healthy male and female subjects, who were not using any drugs, medications or vitamin supplementations. Individuals with cardiovascular disease, cancer and diabetes were not included in this study. Women who were pregnant were not included in this study. All subjects were ethnic Norwegian. The participants reported that they were not suffering from any disease. Based on their self-reported health evaluation, apparently healthy employees and students $(n=103)$ from University of Agder, Kristiansand, Norway, agreed to participate in the study (Fig. 1). One hundred and three subjects were randomized for supplementation. During the first supplementation trial, they were given either folic acid $(0.8 \mathrm{mg}$ folic acid/per day) $(n=52)$ or placebo $(n=51)$ for a period of 14 days. Twelve subjects dropped out, and 91 subjects completed the study (Fig. 1). Fasting blood samples were collected before and after the supplementation period. Individuals who received folic acid during the first trial received placebo during the second trial and vice versa. Washout period between the two trials was 14 days. All subjects provided fasting blood sample in the morning 


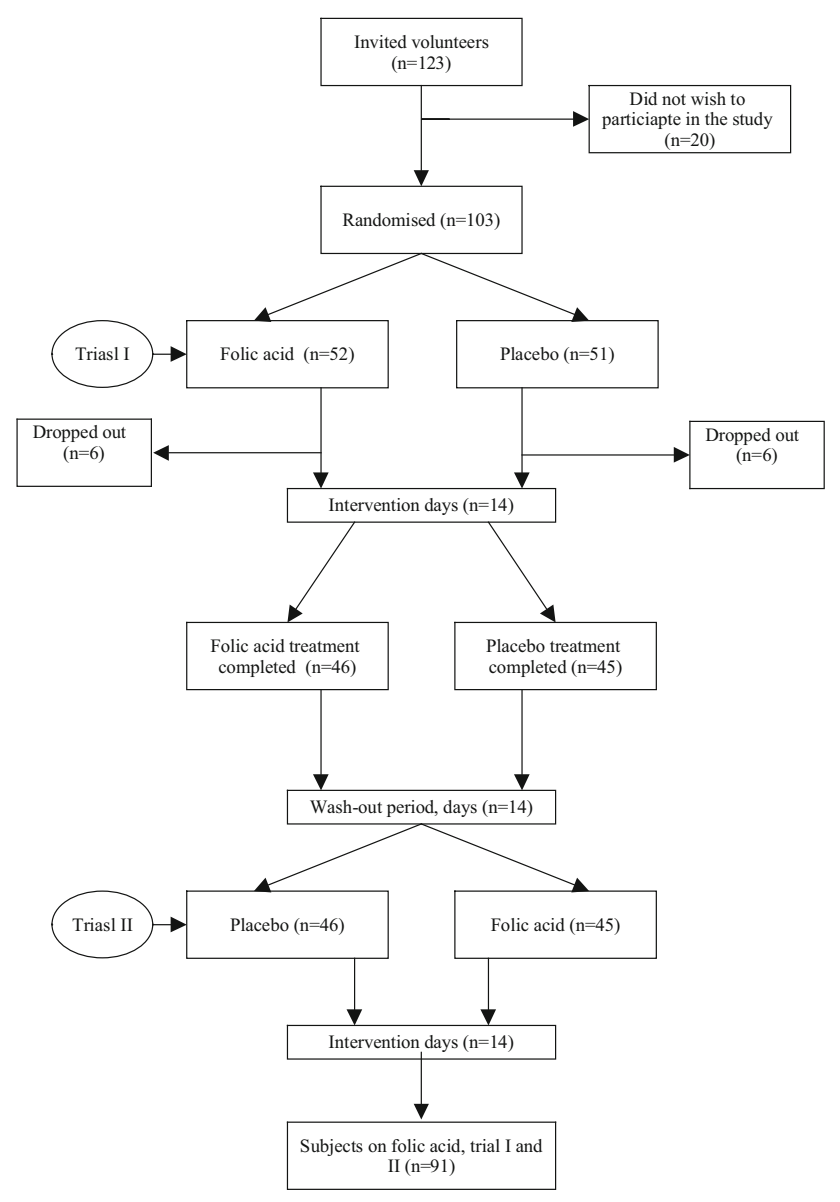

Fig. 1 Flow chart diagram shows the steps taken for the collection of blood samples from healthy subjects before and after supplementation with folic acid and placebo

(between 7 am and 9 am) on day 1 (1 day before folic acid supplementation), day 15 , day 30 and day 45. Blood samples were placed on the ice in the dark. Blood was used for the isolation of DNA. Serum and plasma were isolated from the blood samples and were stored at $-80{ }^{\circ} \mathrm{C}$ until all biochemical and molecular biology analyses were performed. Data from subjects on folic acid supplementation $(n=91)$ and subjects on placebo $(n=46)$ were used for statistical analyses.

Dietary intake data were collected during the first trial; the data were available from 96 subjects, who had also provided the blood samples at the first meeting. Findings on the dietary intake data were reported previously (Hernes et al. 2012).

We have reported previously that folic acid supplement, $0.6 \mathrm{mg}$ folic acid, given to healthy individuals increased the concentration of serum folate significantly after 5 weeks (Mansoor et al. 1999). Based on these observations, we calculated the sample size based on $80 \%$ power.

The present study was performed according to the guidelines established in Declaration of Helsinki. The study protocol was approved by the Regional Committee of Ethics, Oslo and Data Inspectorate in Norway.

\section{Genotyping}

Briefly, reaction volume $20 \mu \mathrm{L}$ contained $1 \times$ Amplitaq Gold reaction buffer, $500 \mu \mathrm{M}$ dNTP, $0.5 \mu \mathrm{M}$ of each primer (primer sequences are provided in Table 1), $1.25 \mathrm{U}$ Amplitaq Gold DNA polymerase (Life Technologies Inc.), $3 \mathrm{mM} \mathrm{MgCl}_{2}$ for all polymorphisms except DHFR-19del and TS, where $1.5 \mathrm{mM} \mathrm{MgCl}_{2}$ was used and $200 \mathrm{ng}$ DNA. PCR profile was $95{ }^{\circ} \mathrm{C}, 5 \mathrm{~min}$, followed by 35 cycles of $95{ }^{\circ} \mathrm{C}, 30 \mathrm{~s}$, the annealing temperature as specified in Table $1,30 \mathrm{~s}, 72{ }^{\circ} \mathrm{C}, 30 \mathrm{~s}$ and final extension incubation at $72{ }^{\circ} \mathrm{C}$ for $7 \mathrm{~min}$. Some of the polymorphisms were analyzed by cutting $10 \mu \mathrm{l}$ PCR products with restriction enzyme with the corresponding buffer, at $37{ }^{\circ} \mathrm{C}$, overnight. The products, after PCR and cutting, were analyzed by the agarose gel electrophoresis (Fredriksen et al. 2007; Charasson et al. 2009; Frosst et al. 1995; Markan et al. 2007; Gemmati et al. 2009; Horie et al. 1995; Skibola et al. 2002; Canalle et al. 2006). In DHFR-19 del, where a 19 nucleotide deletion (D) in intron 1 or wild type, no deletion (W) was detected. In TS, doublets (2R) or triplets (3R) of an element of 28 nucleotides in the promoter of the gene were detected. The resulting product sizes for the gene polymorphisms are given in Table 1. Details of the PCR methods have been provided previously (Cabo et al. 2015).

Measurement of folate and vitamin $\mathrm{B}_{12}$ in the serum samples

The concentrations of serum folate and serum vitamin $B_{12}$ were measured by a Cobas 6000 in the laboratory of Medical Biochemistry, Sørlandet Hospital HF, Arendal, Norway. The coefficient for variation (CV) for the assays for serum folate and vitamin B12 was $<10 \%$.

\section{Measurement of p-tHcy}

The concentration of p-tHcy was measured by an ion-pair high-performance liquid chromatography (HPLC) method with a fluorescence detector (Mansoor et al. 1992). The HPLC method had a CV $<8 \%$ for the p-tHcy measurements.

Statistical methods

Data are presented as mean and standard deviation $( \pm \mathrm{SD})$. The concentrations of serum folate and p-tHcy had not normal distribution (Gaussian distribution curve); therefore, we used the log-converted values of serum folate and p-tHcy in statistical analyses (Mansoor et al. 1995). We 
Table 1 PCR methods used in this study

\begin{tabular}{|c|c|c|c|c|c|c|}
\hline Gene & & Primers & $\begin{array}{l}\text { Annealing } \\
\text { temperature } \\
\text { in PCR }\left({ }^{\circ} \mathrm{C}\right)\end{array}$ & $\begin{array}{l}\text { Restriction } \\
\text { enzyme }\end{array}$ & $\begin{array}{l}\text { PCR } \\
\text { product (bp) }\end{array}$ & References \\
\hline \multirow[t]{2}{*}{$\begin{array}{l}\text { MTHFR- } \\
677 \mathrm{C}>\mathrm{T}\end{array}$} & $(\mathrm{S})$ & TGAAGGAGAAGGTGTCTGCGGGA & 55 & Hinf & $198,175,23$ & $\begin{array}{l}\text { Fredriksen et al. (2007), Charasson } \\
\text { et al. (2009), Frosst et al. (1995), } \\
\text { Markan et al. (2007) }\end{array}$ \\
\hline & (AS) & AGGACGGTGCGGTGAGAGTG & & & & \\
\hline \multirow[t]{2}{*}{$\begin{array}{l}\text { MTHFR- } \\
1298 \mathrm{~A}>\mathrm{C}\end{array}$} & $(\mathrm{S})$ & CTTTGGGGAGCTGAAGGACTACTA & 55 & MboII & $\begin{array}{l}84,56,31 \\
30,28,18\end{array}$ & $\begin{array}{l}\text { Fredriksen et al. (2007), Charasson } \\
\text { et al. (2009), Frosst et al. (1995), } \\
\text { Markan et al. (2007) }\end{array}$ \\
\hline & (AS) & CACTTTGTGACCATTCCGGTTTG & & & & \\
\hline \multirow[t]{2}{*}{$\begin{array}{l}\text { RFC1- } \\
\qquad 80 \mathrm{G}>\mathrm{A}\end{array}$} & $(\mathrm{S})$ & AGTGTCACCTTCGTCCCCTC & 55 & CfoI & $\begin{array}{l}162,125,68 \\
37\end{array}$ & $\begin{array}{l}\text { Fredrikson et al. (2007), Markan } \\
\text { et al. (2007) }\end{array}$ \\
\hline & (AS) & CTCCCGCGTGAAGTTCTT & & & & \\
\hline \multirow[t]{2}{*}{$\begin{array}{l}\text { MTHFD1- } \\
1958 \mathrm{G}>\mathrm{A}\end{array}$} & $(\mathrm{S})$ & CACTCCAGTGTTTGTCCATG & 55 & MspI & $\begin{array}{l}267,196,70 \\
\quad 56,8\end{array}$ & $\begin{array}{l}\text { Fredriksen et al. (2007), } \\
\text { Charasson et al. (2009), Markan } \\
\text { et al. (2007) }\end{array}$ \\
\hline & (AS) & GCATCTTGAGAGCCCTGAC & & & & \\
\hline \multirow[t]{2}{*}{$\begin{array}{l}\text { MTR- } \\
2756 \mathrm{~A}>\mathrm{G}\end{array}$} & $(\mathrm{S})$ & TGTTCCCAGCTGTTAGATGAAAAT & 55 & HaeIII & $211,131,80$ & $\begin{array}{l}\text { Fredriksen et al. (2007), } \\
\text { Charasson et al. (2009) }\end{array}$ \\
\hline & (AS) & GATCCAAAGCCTTTTACACTCCTC & & & & \\
\hline \multirow[t]{3}{*}{$\begin{array}{l}\text { DHFR- } \\
19 \mathrm{del}\end{array}$} & $(\mathrm{F} 1)$ & CCACGGTCGGGGTACCTGGG & 63 & & 113,92 & $\begin{array}{l}\text { Gemmati et al. (2009), Horie et al. } \\
\text { (1995), Skibola et al. (2002), } \\
\text { Canalle et al. (2006) }\end{array}$ \\
\hline & $(\mathrm{F} 2)$ & ACGGTCGGGGTGGCCGAC & & & & \\
\hline & $(\mathrm{R})$ & AAAAGGGGAATCCAGTCGG & & & & \\
\hline \multirow[t]{3}{*}{ TS } & (P1) & GTGGCTCCTGCGTTTCCCCC & 62 & & & $\begin{array}{l}\text { Gemmati et al. (2009), Horie et al. } \\
\text { (1995), Skibola et al. (2002), } \\
\text { Canalle et al. (2006) }\end{array}$ \\
\hline & (P2) & CCAAGCTTGGCTCCGAGCCGG & & & & \\
\hline & & CCACAGGCATGGCGCGG & & & & \\
\hline
\end{tabular}

MTHFR methylene tetrahydrofolate reductase, RFC1 reduced folate carrier protein-1, MTHFD 1 methylenetetrahydrofolate dehydrogenase 1 , $M T R$ methionine synthase, DHFR dihydrofolate reductase, $T S$ thymidylate synthase

tested differences between two groups by Student $t$ test, and the differences between more than two groups were estimated by ANOVA. $p$ values $<0.05$ were considered significant. We used ANOVA post hoc Bonferroni test for multiple comparisons to explore the effect of genotype groups on the concentration of serum folate and p-tHcy. In this test, $p$ value required for statistical significance was much lower than 0.05. Age and BMI were compared between the groups by a nonparametric Mann-Whitney $U$ test. Kruskal-Wallis test was used for testing comparison between three parameters. Hardy-Weinberg equilibrium (HWE) was examined with Chi-square test. We used Statview 4.5 for the Macintosh for the statistical analyses.

\section{Results}

The characteristics of the study participants and the concentrations of serum folate and p-tHcy are reported in
Table 2. The concentration of serum folate increased and the concentration of p-tHcy decreased after folic acid supplementation ( $p<0.0001$ and $p=0.0001)$; an increase in the concentration of serum folate was $23.0 \pm 30.6 \mathrm{nmol} / \mathrm{L}$ (mean $\pm \mathrm{SD}$ ) and a decrease in the concentration of p-tHcy was $0.7 \pm 1.4 \mu \mathrm{mol} / \mathrm{L}$ (mean $\pm \mathrm{SD}$ ) (Table 2). The baseline concentration of serum folate in the employees was not significantly higher than in the students $(p=0.2)$. However, the concentration of serum folate increased significantly higher in the employees than in the students ( $p=0.006)$. Only one subject had hyperhomocysteinemia; the p-tHcy concentration was $>15 \mu \mathrm{mol} / \mathrm{L}$. None of the study subjects had deficiency of serum folate. Allele frequency for genes has been tested for Hardy-Weinberg equilibrium and is provided in Table 3.

The subjects on folic acid supplementation had higher concentration of serum folate after washout and placebo periods than the baseline concentrations $22.04 \pm 6.67$ versus $18.05 \pm 6.45 \mathrm{nmol} / \mathrm{L}($ mean $\pm \mathrm{SD})(p<0.001)$. 
Table 2 Age and BMI of the study subjects and the concentrations of serum folate and p-tHcy before and after folic acid supplementation

\begin{tabular}{|c|c|c|c|}
\hline & All & Employees & Students \\
\hline $\begin{array}{l}\text { Folic acid group, } \\
\text { number }\end{array}$ & 91 & 49 & 42 \\
\hline Age, years & $53.5 \pm 7.0$ & $24.3 \pm 3.2^{* 1}$ & \\
\hline BMI & & $24.7 \pm 3.3$ & $23.9 \pm 3.6$ \\
\hline $\begin{array}{l}\text { Sex, female/male } \\
\text { ratio }\end{array}$ & $71 / 24$ & & \\
\hline $\begin{array}{l}\text { Serum folate, } \\
\mathrm{nmol} / \mathrm{L}\end{array}$ & $17.2 \pm 6.3$ & $18.0 \pm 4.8$ & $16.3 \pm 5.5$ \\
\hline $\begin{array}{l}\text { Serum folate, post- } \\
\text { intervention }\end{array}$ & $40.1 \pm 30.7^{\# 1}$ & $48.1 \pm 38.7^{*^{2}}$ & $30.6 \pm 11.1^{*}$ \\
\hline $\mathrm{p}$-tHcy, $\mu \mathrm{mol} / \mathrm{L}$ & $8.4 \pm 3.5$ & $8.6 \pm 2.3$ & $8.2 \pm 4.5$ \\
\hline $\begin{array}{l}\text { p-tHcy, post- } \\
\text { intervention }\end{array}$ & $7.8 \pm 3.0^{\# 2}$ & $8.2 \pm 2.2^{* 4}$ & $7.4 \pm 3.8^{* 5}$ \\
\hline $\begin{array}{l}\text { Placebo group, } \\
\text { number }\end{array}$ & 46 & & \\
\hline $\begin{array}{l}\text { Serum folate, } \\
\mathrm{nmol} / \mathrm{L}\end{array}$ & $16.5 \pm 5.6$ & & \\
\hline $\begin{array}{l}\text { Serum folate, post- } \\
\text { intervention }\end{array}$ & $17.5 \pm 6.3^{* 6}$ & & \\
\hline $\mathrm{p}$-tHcy, $\mu \mathrm{mol} / \mathrm{L}$ & $8.8 \pm 4.3$ & & \\
\hline $\begin{array}{l}\text { p-tHcy, post- } \\
\text { intervention }\end{array}$ & $8.6 \pm 2.9$ & & \\
\hline Female/male ratio & $71 / 24$ & & \\
\hline
\end{tabular}

Data are presented as mean \pm SD. Log-converted values of serum folate and p-tHcy were used in the analyses

${ }^{1} p<0.0001, *^{2} p<0.0001, *^{3} p<0.0001, *^{4} p=0.009$, $*^{5} p=0.007, *^{6} p=0.01,{ }^{\# 1}$ baseline concentrations versus after supplementation $-p<0.0001,{ }^{\# 2}$ baseline concentration versus after treatment $-p=0.0001$

Therefore, the combined data on folic acid supplementation from trial I and trial II $(n=91)$ and placebo treatment data from trial I $(n=45)$ were used in the statistical analysis.

There was a significant difference in the concentration of serum folate and p-tHcy in individuals with MTHFR677CC, CT and TT genotypes after folic acid supplementation ( $p=0.01$ and $p=0.0006$ ) (Table 3).

We combined homozygote (wild type), heterozygote and homozygote (variant type) for MTHFR-677C $>$ T versus MTHFR-1298A $>$ C, RFC1-80G $>$ A, MTHFD11958G $>$ A, MTR-2756A $>$ G, DHFR-19 del and TS polymorphisms into groups. The effect of polymorphism combinations on the concentrations of serum folate and p-tHcy was explored by multiple comparisons.

The baseline concentration of serum folate was significantly different in RFC1-80 polymorphism combinations alone $(p=0.03)$ Table 4 . The concentration was highest in RFC1-AA and MTHFR677 CT and TT than other polymorphism combinations $(p=0.002)$ (Table 4$)$.

The increase in the concentration of serum folate was significantly different in different genotype combinations,
MTHFR677 versus MTHFR1298, MTHFD11958, MTR2756, TS and RFC1-80 $(p=0.02, \quad p=0.03$, $p=0.03, p=0.04$ and $p=0.0003$ ) (Table 4).

The concentration of serum folate in MTHFR1298AC and CC and MTHFR677CC combination was significantly higher than MTHFR1298AC and CC and MTHFR677CT and TT combination $(p=0.005)$. MTHFD1-1958GA and AA and MTHFR677CC also showed a significant difference in the concentration of serum folate than MTHFD11958GG and MTHFR677CT and TT $(p=0.003)$. Similar observations were done for TS-2R2R and TS-2R3R and MTHFR677CC versus TS-2R2R and TS-2R3R and MTHFR677CT and TT $(p=0.008)$. The most significant differences were observed for RFC1GA and MTHFR677CC versus RFC1GG and MTHFR677CT and TT and RFC1GA, MTHFR677CC versus RFC1GA and MTHFR677CT and TT $(p<0.0001$ and $p=0.0002)$ (Table 4).

In Table 5, we could show that the baseline concentration of p-tHcy was significantly different in combined polymorphisms, MTHFR677 versus MTHFR1298, MTHFD1-1958. MTR2756, DHFR19Del, TS and RFC1-80 $(p=0.002, p=0.007, p=0.007, p=0.006, p=0.006$ and $p=0.01$ ). The combination MTHFR1298AA and MTHFR677CC polymorphisms had lower p-tHcy concentration than MTHFR1298AA and MTHFR677CT and TT $(p=0.0003)$. The MTHFD1-1958GA and AA and MTHFR677CC had also significantly lower concentration of p-tHcy than MTHFD1-1958GA and AA and MTHFRCT and TT $(p=0.004)$. MTR2756AG and GG and MTHFR677CC versus MTR2756AG and GG and MTHFR677CT and TT had difference in the concentration of p-tHcy (0.004). Similar observations were done for two different combinations of DHFR19Del and MTHFR677 ( $p=0.002$ and $p=0.002$ ), one for TS and MTHFR677 $(p=0.008)$ and one for RFC1-80 and MTHFR677 $(p=0.001)($ Table 5).

The concentrations of serum vitamin $\mathrm{B}_{12}$ and p-tHcy were significantly higher in individuals with MTHFR$677 \mathrm{C}>\mathrm{T}-\mathrm{TT}$ than in individuals with $\mathrm{CC}$ and $\mathrm{CT}$ polymorphisms $(p<0.05$ and $p<0.05)$.

Vitamin $B_{12}$, vitamin $B_{2}$ and protein intakes were significantly different in individuals with MTHFR-1298A $>$ C polymorphisms $(p<0.05, p<0.05$ and $p<0.05$, respectively). Similarly, vitamin $B_{12}$ intake was significantly different in individuals with DHFR-19del polymorphism $(p<0.05)$ (Table 6).

\section{Discussion}

The baseline concentrations of serum folate and p-tHcy in the study subjects are in accordance with the previously 
Table 3 Concentrations of serum folate and p-tHcy after folic acid supplementation according to the genotypes

\begin{tabular}{|c|c|c|c|c|c|c|c|}
\hline & \multicolumn{4}{|c|}{ Serum folate over baseline and after supplementation } & \multicolumn{3}{|c|}{ p-tHcy over baseline and after supplementation } \\
\hline & Allele frequency & Baseline & After supplementation & $p$ value & Baseline & After supplementation & $p$ value \\
\hline \multicolumn{8}{|l|}{$M T H F R-677 C>T$} \\
\hline $\mathrm{CC}(n=40)$ & C:0.67 & $18.0 \pm 6.2$ & $49.5 \pm 40.1^{*}$ & $<0.0001$ & $7.3 \pm 1.9$ & $7.0 \pm 1.4 * *$ & 0.22 \\
\hline $\mathrm{CT}(n=43)$ & T:0.33 & $16.4 \pm 5.8$ & $34.6 \pm 20.0$ & $<0.0001$ & $8.7 \pm 2.3$ & $7.8 \pm 2.0$ & $<0.0001$ \\
\hline $\mathrm{TT}(n=8)$ & & $17.8 \pm 9.0$ & $26.0 \pm 9.4$ & 0.005 & $12.6 \pm 8.9$ & $11.7 \pm 7.6$ & 0.32 \\
\hline \multicolumn{8}{|c|}{ MTHFR-1298A>C } \\
\hline AA $(n=46)$ & A:0.69 & $17.9 \pm 6.5$ & $35.5 \pm 19.3$ & $<0.0001$ & $8.9 \pm 4.5$ & $8.2 \pm 3.9$ & 0.01 \\
\hline $\mathrm{AC}(n=34)$ & C:0.31 & $16.7 \pm 6.3$ & $43.2 \pm 35.7$ & $<0.0001$ & $8.2 \pm 2.0$ & $7.5 \pm 1.5$ & 0.007 \\
\hline $\mathrm{CC}(n=11)$ & & $15.7 \pm 5.4$ & $50.3 \pm 48.8$ & 0.0003 & $7.3 \pm 1.7$ & $7.0 \pm 1.6$ & 0.3 \\
\hline \multicolumn{8}{|l|}{$R F C 1-80 G>A$} \\
\hline GG $(n=26)$ & G:51 & $16.6 \pm 5.1$ & $30.8 \pm 11.4$ & $<0.0001$ & $8.1 \pm 1.9$ & $7.4 \pm 1.4$ & 0.04 \\
\hline GA $(n=41)$ & A:49 & $16.3 \pm 6.0$ & $41.6 \pm 33.3$ & $<0.0001$ & $8.7 \pm 4.6$ & $8.0 \pm 3.8$ & 0.02 \\
\hline AA $(n=24)$ & & $19.4 \pm 7.5$ & $47.4 \pm 37.6$ & $<0.0001$ & $8.3 \pm 2.5$ & $7.8 \pm 2.4$ & 0.02 \\
\hline \multicolumn{8}{|c|}{ MTHFD1-1958G>A } \\
\hline $\mathrm{GG}(n=32)$ & G:0.58 & $16.9 \pm 6.2$ & $37.8 \pm 29.5$ & $<0.0001$ & $8.3 \pm 1.8$ & $7.5 \pm 1.4$ & 0.3 \\
\hline $\mathrm{GA}(n=41)$ & A:0.42 & $16.4 \pm 4.6$ & $41.0 \pm 35.0$ & $<0.0001$ & $8.6 \pm 4.7$ & $8.1 \pm 4.0$ & 0.02 \\
\hline $\mathrm{AA}(n=18)$ & & $19.7 \pm 9.0$ & $42.0 \pm 21.2$ & $<0.0001$ & $8.3 \pm 2.5$ & $7.6 \pm 2.2$ & 0.003 \\
\hline \multicolumn{8}{|l|}{$M T R-2756 A>G$} \\
\hline $\mathrm{AA}(n=54)$ & A: 0.78 & $17.3 \pm 6.5$ & $43.2 \pm 35.2$ & $<0.0001$ & $8.3 \pm 2.3$ & $7.7 \pm 1.9$ & 0.008 \\
\hline $\mathrm{AG}(n=34)$ & G:0.22 & $17.4 \pm 6.1$ & $35.4 \pm 22.1$ & $<0.0001$ & $8.5 \pm 4.9$ & $7.7 \pm 4.2$ & 0.005 \\
\hline $\mathrm{GG}(n=3)$ & & $15.0 \pm 4.1$ & $35.1 \pm 15.8$ & 0.02 & $9.7 \pm 5.5$ & $9.6 \pm 5.0$ & 0.9 \\
\hline \multicolumn{8}{|l|}{ DHFR-19del } \\
\hline $\mathrm{WW}(n=34)$ & W:0.59 & $16.3 \pm 5.2$ & $42.3 \pm 35.6$ & $<0.0001$ & $8.4 \pm 2.2$ & $7.7 \pm 1.7$ & 0.06 \\
\hline $\mathrm{WD}(n=36)$ & D:0.41 & $17.7 \pm 6.9$ & $34.0 \pm 22.0$ & $<0.0001$ & $8.6 \pm 4.9$ & $8.1 \pm 4.4$ & 0.14 \\
\hline $\mathrm{DD}(n=21)$ & & $18.0 \pm 6.8$ & $46.3 \pm 33.5$ & $<0.0001$ & $8.1 \pm 2.3$ & $7.4 \pm 1.7$ & 0.0006 \\
\hline \multicolumn{8}{|l|}{$T S$} \\
\hline $2 \mathrm{R} 2 \mathrm{R}(n=22)$ & 2R:0.50 & $18.3 \pm 8.4$ & $37.2 \pm 26.4$ & $<0.0001$ & $8.2 \pm 2.7$ & $7.5 \pm 2.1$ & 0.25 \\
\hline $2 \mathrm{R} 3 \mathrm{R}(n=46)$ & $3 \mathrm{R}: 0.50$ & $17.4 \pm 5.5$ & $40.1 \pm 30.9$ & $<0.0001$ & $8.8 \pm 4.5$ & $8.1 \pm 3.9$ & 0.002 \\
\hline $3 \mathrm{R} 3 \mathrm{R}(n=23)$ & & $15.9 \pm 5.3$ & $42.7 \pm 34.6$ & $<0.0001$ & $7.9 \pm 1.5$ & $7.4 \pm 1.6$ & 0.03 \\
\hline
\end{tabular}

Data are presented as mean $\pm \mathrm{SD}$

$* p=0.01$, and $* * p=0.0006$ ANOVA test. The genotype distribution for each polymorphism was tested for possible deviation from HWE

published findings (Mansoor et al. 2011). The increase, $23.0 \pm 30.6 \mathrm{nmol} / \mathrm{L}$ (mean $\pm \mathrm{SD}$ ), in the concentration of serum folate and a decrease, $0.7 \pm 1.4 \mu \mathrm{mol} / \mathrm{L}$ (mean $\pm \mathrm{SD}$ ), in the concentration of $\mathrm{p}$-tHcy after folic acid supplementation, $0.8 \mathrm{mg} / \mathrm{day}$, for 2 weeks, are similar to the findings, in healthy subjects, reported previously, increase in serum folate $18.0 \pm 1.5 \mathrm{nmol} / \mathrm{L}($ mean $\pm \mathrm{SD})$ and a decrease in p-tHcy $0.9 \pm 0.4 \mu \mathrm{mol} / \mathrm{L}$ (mean \pm SD) (Araki et al. 2006). It has also been demonstrated that folic acid dose, $0.8 \mathrm{mg} /$ day given to healthy subjects, for 12 weeks, increased the concentration of serum folate from $12.9 \pm 3.6$ to $53.4 \pm 28.3 \mathrm{nmol} / \mathrm{L}($ mean $\pm \mathrm{SD})$ and reduced the concentration of p-tHcy from $11.5 \pm 2.8$ to $9.6 \pm 2.2 \mu \mathrm{mol} /($ mean $\pm \mathrm{SD}$ ) (change about $25 \%$ ) (Van Oort et al. 2003). It has been reported that the higher is the baseline concentration of p-tHcy, the greater is the reduction in the concentration of p-tHcy after vitamin $\mathrm{B}_{12}$ or folic acid therapy (Mansoor et al. 1999; Homocysteine lowering trialists' collaboration 2005; Green 2011; Mansoor et al. 2013).

The concentration of serum folate, 5-methyl-THF, increased significantly higher in subjects with higher age than in subjects with the lower age (Table 2). This observation may suggest that age may affect folate kinetics during increased bioavailability of folate. Probably, the concentration of serum folate increases when the folatebinding sites on the intracellular proteins are saturated or the cells are unable to utilize the surplus folate in the regular biochemical reactions.

The baseline concentration of serum folate was not altered significantly by all polymorphisms in folate genes as reported previously (Table 3) (Pereira et al. 2004; Devlin 
Table 4 Concentration of serum folate associated with combined polymorphisms before and after supplementation with folic acid

$\begin{array}{llll}\begin{array}{l}\text { Baseline } \\ \text { serum folate }\end{array} & \begin{array}{l}p \text { value for the comparison } \\ \text { between polymorphism } \\ \text { combinations }\end{array} & \begin{array}{l}\text { After 2 weeks } \\ \text { serum folate }\end{array} & \begin{array}{l}p \text { value for the comparison } \\ \text { between polymorphism } \\ \text { combinations }\end{array}\end{array}$

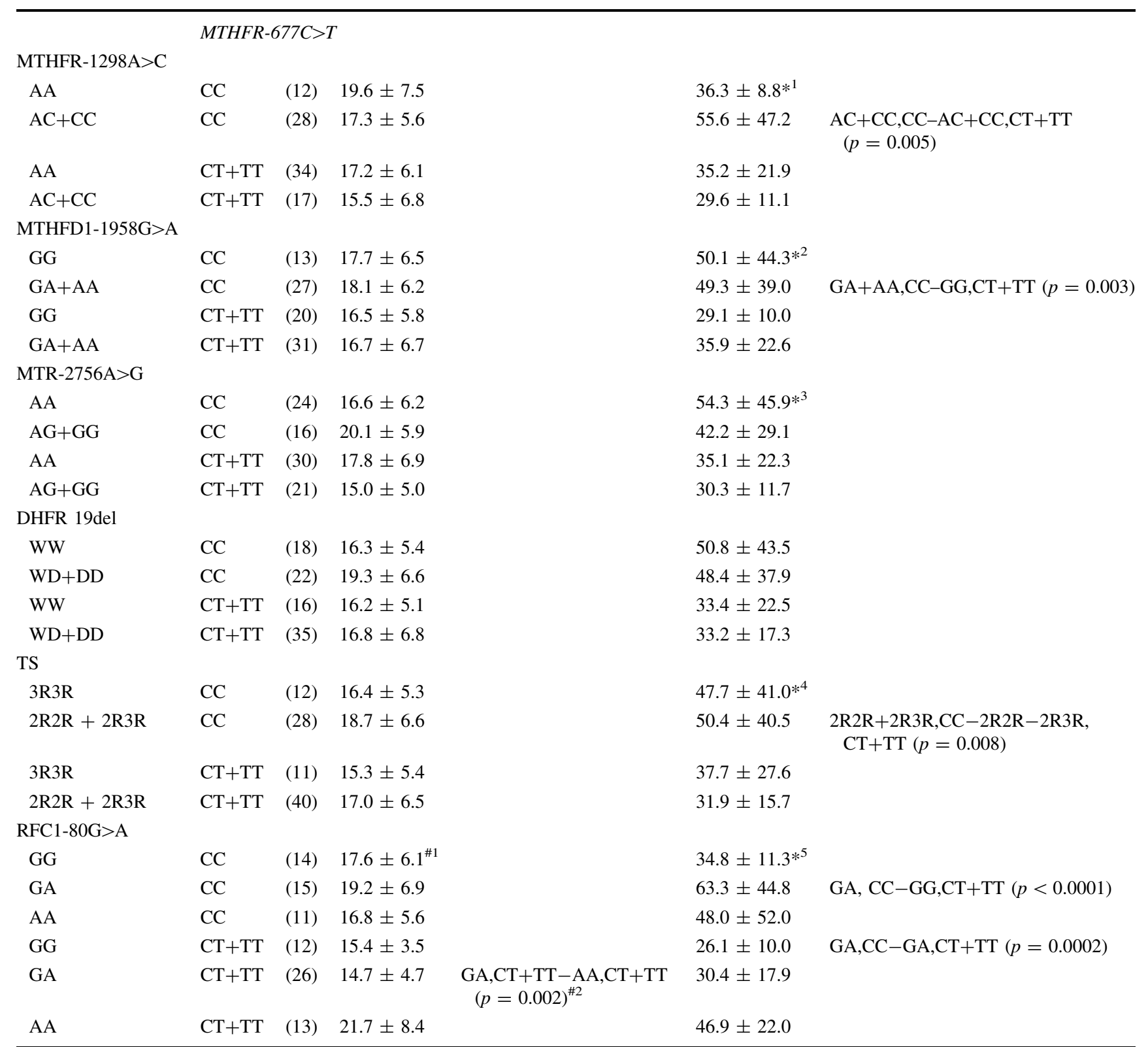

Data are presented as mean \pm SD. Number of subjects in parentheses. Serum folate concentration is given in nmol/L. ANOVA test

${ }^{\# 1} p=0.03,{ }^{\# 2} p=0.002,{ }^{* 1} p=0.02, *^{2} p=0.03, *^{3} p=0.03,{ }^{*}{ }^{4} p=0.04,{ }^{*}{ }^{5} p=0.0003$

et al. 2006; Zappacosta et al. 2014; Yang et al. 2008; Anderson et al. 2013; Nelen et al. 1998; DeVos et al. 2008). After the folic acid supplementation, the concentration of serum folate was changed significantly by MTHFR-677 $>$ T polymorphisms (Table 3). However, the combination of MTHFR677 and RFC1-80 had a significant impact on the baseline concentration of serum folate (Table 4). The highest baseline serum folate concentration, $21.7 \pm 8.4 \mathrm{nmol} / \mathrm{L}$ (mean $\pm \mathrm{SD}$ ), was detected in subjects with RFC1-80AA and MTHFR-677 CT+TT combination, whereas the lowest baseline serum folate concentration, $14.7 \pm 4.7 \mathrm{nmol} / \mathrm{L}$, was measured in subjects with RFC1$80 \mathrm{GA}$ and MTHFR-677CT+TT combination $(p=0.002)$ (Table 4). Furthermore, after folic acid supplementation, the subjects with MTHFR-677 CC and RFC1-80GA polymorphisms had the greatest increase in the concentration of serum folate, whereas the subjects with combination of MTHFR677 CT+TT and RFC1-80GG had the 
Table 5 Concentration of p-tHcy associated with combined genotypes before and after supplementation with folic acid

\begin{tabular}{|c|c|c|c|c|c|c|}
\hline & & & $\begin{array}{l}\text { Baseline } \\
\text { p-tHcy }\end{array}$ & $\begin{array}{l}p \text { value for the comparison } \\
\text { between combined polymorphisms }\end{array}$ & $\begin{array}{l}2 \text { weeks } \\
\text { p-tHcy }\end{array}$ & $\begin{array}{l}p \text { value for the comparison } \\
\text { between combined polymorphisms }\end{array}$ \\
\hline & \multicolumn{5}{|c|}{ MTHFR-677C >T } & \\
\hline \multicolumn{7}{|l|}{$\begin{array}{l}\text { MTHFR- } \\
1298 \mathrm{~A}>\mathrm{C}\end{array}$} \\
\hline AA & $\mathrm{CC}$ & $(12)$ & $6.6 \pm 2.2^{* 1}$ & & $6.7 \pm 1.4$ & \\
\hline $\mathrm{AC}+\mathrm{CC}$ & $\mathrm{CC}$ & $(28)$ & $7.6 \pm 1.7$ & $\mathrm{AA}, \mathrm{CC}-\mathrm{AA}, \mathrm{CT}+\mathrm{TT}(p=0.0003)$ & $7.1 \pm 1.4$ & \\
\hline AA & $\mathrm{CT}+\mathrm{TT}$ & $(34)$ & $9.6 \pm 4.8$ & & $8.7 \pm 4.3$ & \\
\hline $\mathrm{AC}+\mathrm{CC}$ & $\mathrm{CT}+\mathrm{TT}$ & $(17)$ & $8.6 \pm 2.3$ & & $7.7 \pm 1.8$ & \\
\hline \multicolumn{7}{|l|}{$\begin{array}{l}\text { MTHFD1- } \\
\text { 1958G }>\text { A }\end{array}$} \\
\hline GG & $\mathrm{CC}$ & (13) & $7.7 \pm 1.6^{*^{2}}$ & & $7.5 \pm 1.3$ & \\
\hline $\mathrm{GA}+\mathrm{AA}$ & $\mathrm{CC}$ & $(27)$ & $7.2 \pm 2.1$ & $\begin{array}{l}\mathrm{GA}+\mathrm{AA}, \mathrm{CC}-\mathrm{GA}+\mathrm{AA}, \mathrm{CT}+\mathrm{TT} \\
\quad(p=0.004)\end{array}$ & $6.8 \pm 1.4$ & $\begin{array}{l}\mathrm{GA}+\mathrm{AA}, \mathrm{CC}-\mathrm{GA}+\mathrm{AA}, \mathrm{CT}+\mathrm{TT} \\
\quad(p=0.002)\end{array}$ \\
\hline GG & $\mathrm{CT}+\mathrm{TT}$ & $(20)$ & $8.8 \pm 1.8$ & & $7.5 \pm 1.4$ & \\
\hline $\mathrm{GA}+\mathrm{AA}$ & $\mathrm{CT}+\mathrm{TT}$ & $(31)$ & $9.6 \pm 5.1$ & & $8.9 \pm 4.5$ & \\
\hline \multicolumn{7}{|l|}{ MTR-2756A $>$ G } \\
\hline AA & $\mathrm{CC}$ & $(24)$ & $7.6 \pm 2.2^{* 3}$ & & $7.3 \pm 1.6$ & \\
\hline $\mathrm{AG}+\mathrm{GG}$ & $\mathrm{CC}$ & $(16)$ & $6.9 \pm 1.2$ & $\begin{array}{l}\mathrm{AG}+\mathrm{GG}, \mathrm{CC}-\mathrm{AG}+\mathrm{GG}, \mathrm{CT}+\mathrm{TT} \\
(p=0.004)\end{array}$ & $6.5 \pm 0.8$ & \\
\hline AA & $\mathrm{CT}+\mathrm{TT}$ & $(30)$ & $8.8 \pm 2.2$ & & $8.0 \pm 2.1$ & \\
\hline $\mathrm{AG}+\mathrm{GG}$ & $\mathrm{CT}+\mathrm{TT}$ & $(21)$ & $10.0 \pm 6.2$ & & $8.9 \pm 5.3$ & \\
\hline \multicolumn{7}{|l|}{ DHFR 19del } \\
\hline WW & $\mathrm{CC}$ & $(18)$ & $7.8 \pm 1.8^{* 4}$ & & $7.1 \pm 1.2$ & \\
\hline WD+DD & $\mathrm{CC}$ & $(22)$ & $7.0 \pm 2.0$ & $\begin{array}{l}\mathrm{WD}+\mathrm{DD}, \mathrm{CC}-\mathrm{WW}, \mathrm{CT}+\mathrm{TT} \\
\quad(p=0.002)\end{array}$ & $6.9 \pm 1.6$ & \\
\hline WW & $\mathrm{CT}+\mathrm{TT}$ & $(16)$ & $9.2 \pm 2.4$ & & $8.3 \pm 2.0$ & \\
\hline WD+DD & $\mathrm{CT}+\mathrm{TT}$ & $(35)$ & $9.3 \pm 4.8$ & $\begin{array}{l}\mathrm{WD}+\mathrm{DD}, \mathrm{CC}-\mathrm{WD}+\mathrm{DD}, \mathrm{CT}+\mathrm{TT} \\
\quad(p=0.002)\end{array}$ & $8.4 \pm 4.3$ & \\
\hline \multicolumn{7}{|l|}{$\mathrm{TS}$} \\
\hline $3 R 3 R$ & $\mathrm{CC}$ & $(12)$ & $7.6 \pm 1.8^{* 5}$ & & $7.0 \pm 1.6$ & \\
\hline $2 \mathrm{R} 2 \mathrm{R}+2 \mathrm{R} 3 \mathrm{R}$ & $\mathrm{CC}$ & $(28)$ & $7.2 \pm 2.0$ & $\begin{array}{l}2 \mathrm{R} 2 \mathrm{R}+2 \mathrm{R} 3 \mathrm{R}, \mathrm{CC}-2 \mathrm{R} 2 \mathrm{R}+2 \mathrm{R} 3 \mathrm{R} \\
\mathrm{CT}+\mathrm{TT}\end{array}$ & $7.0 \pm 1.3$ & \\
\hline $3 R 3 R$ & $\mathrm{CT}+\mathrm{TT}$ & $(11)$ & $8.2 \pm 0.8$ & $(p=0.008)$ & $7.8 \pm 1.5$ & \\
\hline $2 \mathrm{R} 2 \mathrm{R}+2 \mathrm{R} 3 \mathrm{R}$ & $\mathrm{CT}+\mathrm{TT}$ & $(40)$ & $9.6 \pm 4.7$ & & $8.5 \pm 4.1$ & \\
\hline \multicolumn{7}{|l|}{$\mathrm{RFC} 1-80 \mathrm{G}>\mathrm{A}$} \\
\hline GG & $\mathrm{CC}$ & $(14)$ & $7.9 \pm 2.1^{* 6}$ & & $7.3 \pm 1.5$ & \\
\hline GA & $\mathrm{CC}$ & $(15)$ & $6.9 \pm 1.9$ & & $6.9 \pm 1.3$ & \\
\hline AA & $\mathrm{CC}$ & $(11)$ & $7.3 \pm 1.6$ & $\mathrm{GA}, \mathrm{CC}-\mathrm{GA}, \mathrm{CT}+\mathrm{TT}(p=0.001)$ & $6.7 \pm 1.5$ & \\
\hline GG & $\mathrm{CT}+\mathrm{TT}$ & $(12)$ & $8.3 \pm 1.7$ & & $7.5 \pm 1.4$ & \\
\hline GA & $\mathrm{CT}+\mathrm{TT}$ & $(26)$ & $9.8 \pm 5.4$ & & $8.6 \pm 4.5$ & \\
\hline AA & $\mathrm{CT}+\mathrm{TT}$ & (13) & $9.2 \pm 2.8$ & & $8.6 \pm 2.8$ & \\
\hline
\end{tabular}

Data are presented as mean \pm SD. Number of subjects in the parentheses. The concentration of p-tHcy is given $\mu$ mol/L. ANOVA test $*^{1} p=0.002, *^{2} p=0.007, *^{3} p=0.007, *^{4} p=0.006, *^{5} p=0.006, *^{6} p=0.01$

lowest concentration of serum folate $63.3 \pm 44.8$ versus $26.1 \pm 10.0 \mathrm{nmol} / \mathrm{L}($ mean $\pm \mathrm{SD})(p<0.0001)$ (Table 4$)$. These findings suggest that MTHFR-677 CC, probably, ensures increased formation of reduced folates after folic acid supplementation and RFC1-80GA affects their transport across the cell membrane. Therefore, combinations of RFC1-80G $>$ A and MTHFR-677C $>$ T polymorphisms may affect the bioavailability of intracellular and extracellular folate and as a result may disturb the folate homeostasis after folic acid supplementation in healthy 


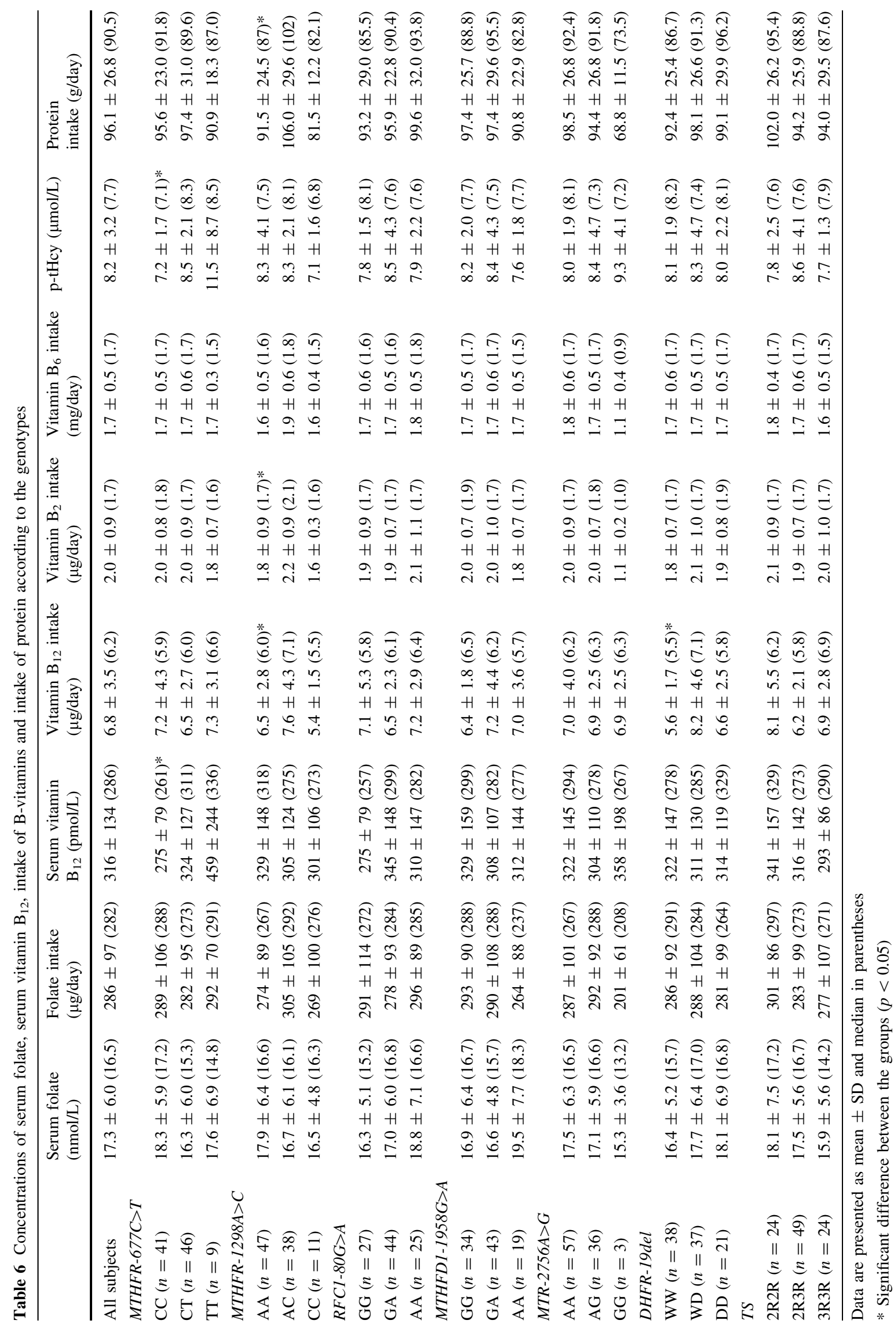


subjects as well as in patients with different diseases (Table 4) (Dufficy et al. 2006). These observations are novel and may suggest that polymorphism combinations, in folate metabolizing genes, may have significant impact on the concentration of serum folate in populations consuming high-dose folic acid supplements and folic acid-fortified foods on daily basis.

As shown in Table 4, MTHFR-677CC and MTHFR1298AC + CC genotypes seem to have an opposite effect on the concentration of serum folate after folic acid supplementation, which is in accordance with a previously published report (Yang et al. 2008).

In subjects on folic acid supplementation, trial I, the concentration of serum folate was still significantly higher after the washout period and the placebo treatment than the baseline concentration. This observation suggests that it takes more than 30 days before the concentration of serum folate reaches to its baseline concentration after termination of folic acid supplements. Previously, even a 30-week washout period after a folic acid supplementation $400 \mu \mathrm{g} /$ day for 12 weeks seemed not to be adequate (Anderson et al. 2013). Thus, these findings suggest that 5-methyl-THF formed after folic acid supplementation accumulates and remains in the serum for longer periods.

The lowest concentration of p-tHcy was detected in subjects with combined polymorphism in MTHFR-677 CC and MTHFR-1298 AA, $6.6 \pm 2.2 \mu \mathrm{mol} / \mathrm{L}($ mean $+\mathrm{SD})$, whereas the subjects with MTR-2756 AG+GG and MTHFR677 CT+TT, and RFC1 GA and MTHFR677 $\mathrm{CT}+\mathrm{TT}$ polymorphisms had the highest concentrations of p-tHcy among six polymorphism combinations tested in this study $(10.0 \pm 6.2$ and $9.8 \pm 5.4 \mu \mathrm{mol} / \mathrm{L}$ (mean $\pm \mathrm{SD}$ ) (Table 5). It has been reported previously that subjects, with MTHFR-677 TT and RFC180 GG combination, have high baseline concentrations of serum homocysteine (Devlin et al. 2006). The possible explanation is the difference in the concentration of serum folate in subjects with these three polymorphism combinations, serum folate $19.6 \pm 7.5,15.0 \pm 5.0$ and $14.7 \pm 4.7 \mathrm{nmol} / \mathrm{L}$, respectively (mean $\pm \mathrm{SD}$ ) (Table 4). The concentrations of p-tHcy and serum folate are within the normal range in these subjects. Our observations that subjects with MTHFR-677 CC, CT and TT have significantly different concentrations of p-tHcy are in accordance with an earlier study (Table 3) (Pereira et al. 2004; Devlin et al. 2006; Zappacosta et al. 2014; Yang et al. 2008; Anderson et al. 2013; Nelen et al. 1998).

Our findings as reported in Table 5 suggest that polymorphisms in genes associated with folate metabolism affect mainly the baseline concentrations of p-tHcy in healthy subjects. It will be interesting to find out whether these polymorphisms have a significant impact on the concentrations of p-tHcy in patients with hyperhomocysteinemia after folic acid supplementation.

We observed a stepwise, gradient, increase in the concentration of serum vitamin $B_{12}$ in subjects with MTHFR677 polymorphisms, $\quad \mathrm{CC}=275 \pm 79 \mathrm{pmol} / \mathrm{L}, \quad \mathrm{CT}=$ $324 \pm 127 \mathrm{pmol} / \mathrm{L}$ and $\mathrm{TT}=459 \pm 244 \mathrm{pmol} / \mathrm{L}$ (mean $\pm \mathrm{SD}$ ) (Table 6). The question is to measure the concentration of serum methylmalonic acid (MMA) and mean corpuscle volume (MCV) in TT individuals to find out whether they have lower intracellular concentrations of vitamin $\mathrm{B}_{12}$ than the individuals with $\mathrm{CC}$ and $\mathrm{CT}$ genotypes. Or this is a random finding? Similarly, intake of vitamin $\mathrm{B}_{12}$, vitamin $\mathrm{B}_{2}$ and proteins may be characterized according to genetic polymorphisms (Table 6); however, we do not have any evidence, which suggests that genetic polymorphisms may affect the intake of micronutrients by healthy subjects. More studies may be required to address these issues.

\section{Possible clinical consequences}

Probably, small serum folate concentration $<10 \mathrm{nmol} / \mathrm{L}$ causes an increase in the concentration of p-tHcy, and serum folate concentration $\geq 12 \mathrm{nmol} / \mathrm{L}$ keeps $\mathrm{p}$-tHcy concentration $<15 \mu \mathrm{mol} / \mathrm{L}$. Furthermore, serum folate concentration $>16 \mathrm{nmol} / \mathrm{L}$ in mothers seems to reduce the risk of NTD in babies (Daly et al. 1995; Shane 2010; Etheredge et al. 2012; Us 1996; Green 2011). Thus, unphysiological serum folate concentration, $\geq 50 \mathrm{nmol} / \mathrm{L}$, may not cause further reduction in the concentration of p-tHcy, neither impact one-carbon metabolism nor affect blood cell homeostasis (Table 5). Previously, elderly, who consumed $600 \mu \mathrm{g}$ folic acid added in the bread, had serum folate concentration from 19.0 to $49.5 \mathrm{nmol} / \mathrm{L}$ and folic acid concentration from 1.03 to $7.22 \mathrm{nmol} / \mathrm{L}$ (Kelly et al. 1997). It was also reported that the individuals who had serum folate concentrations $<50 \mathrm{nmol} / \mathrm{L}$ had only $2.3 \%$ folic acid, but the individuals who had serum folate concentrations $>50 \mathrm{nmol} / \mathrm{L}$ had $15.7 \%$ folic acid in the serum (Pfeiffer et al. 2004). These observations suggest that after folic acid supplementation, folic acid and 5-methyl-THF accumulate in the blood in subjects on high-dose folic acid supplementation. Therefore, the question is whether individuals using high-dose folic acid supplements for long periods may be exposed to transient folic acid stress? Previously, it was reported that folate and zinc had a mutual inhibitory effect at the site of intestinal transport or absorption (Ghishan et al. 1986). It was also reported that women with the highest quartile folate and the lowest quartile zinc were vulnerable to fetomaternal complications (Mukherjee et al. 1984). Recently, it was demonstrated that high-dose folic acid supplements were associated with adverse effects on fetal mouse 
development (Mikael et al. 2013). It was also shown that folic acid supplements $(400 \mu \mathrm{g})$ given every other day to individuals who were consuming diet providing about $3.5 \mathrm{mg}$ zinc were associated with increased loss of zinc via faces (Milne et al. 1984). In patients with cervical dysplasia, the concentration of zinc in blood cells was not reduced significantly, when they consumed $10 \mathrm{mg}$ folic acid daily for 2-4 months (Butterworth et al. 1988). A recent report suggested that high-dose folic acid might promote the progression of mammary tumors in rat (Manshadi et al. 2014). Furthermore, a clinical trial based on vitamins folic acid, vitamin $\mathrm{B}_{12}$ and vitamin $\mathrm{B}_{6}$ supplements was terminated before time due to the concern of possible adverse effects of the B-vitamin supplements in patients with heart disease, even though the concentration of p-tHcy was reduced about $30 \%$ (Ebbing et al. 2008). Nevertheless, no link between folic acid supplementation and CVD and cancer was established (Clarke et al. 2010).

\section{Limitations and strengths}

The washout period in our investigation was short. However, it does not seem to affect the outcome of folic acid supplementation. The number of study subjects might be higher to explore the effect of polymorphisms and age on the concentration of serum folate. However, when the data collected from, subjects on folic acid supplementation participating in, trial I and trial II were combined $(n=91)$, the effect of polymorphism combinations was significant on the pre- and post-intervention concentration of serum folate and p-tHcy. Therefore, in our view, our findings might be useful for designing new studies to assess the effects of increased folic acid consumption on trace element homeostasis and on the concentration of biomarkers for CVD and cancer.

\section{Conclusion}

Combination of MTHFR-677 and RFC-1 polymorphisms has a profound impact on the concentration of serum folate in healthy subjects after short-term folic acid supplementation. Furthermore, polymorphisms in genes coding for folate metabolism affect the baseline concentration of p-tHcy in healthy subjects.

Acknowledgments We are thankful to the participants of the study. We are also grateful to the University of Agder (UiA), Norway, for financial support.

Conflict of interest There is no conflict of interest.

\section{References}

Anderson CA, Beresford SA, McLerran D, Lampe JW, Deeb S, Feng Z, Motulsky AG (2013) Response of serum and red cell folate concentrations to folic acid supplementation depends on methylenetetrahydrofolate reductase genotype: results from a cross over trial. Mol Nutr Food Res 57:637-644

Araki R, Maruyama C, Igarashi S, Yoshida M, Maruyama T, Satoh T, Yoshida M, Umegaki K (2006) Effects of short-term folic acid and riboflavin supplement on serum folate and plasma total homocysteine concentrations in young Japanese male subjects. Eur J Clin Nutr 60:573-579

Butterworth CE Jr, Hatch K, Cole P, Sauberlich HE, Tamura T, Cornwell PE, Soong SJ (1988) Zinc concentration in plasma and erythrocytes of subjects receiving folic acid supplementation. Am J Clin Nutr 47:484-486

Cabo R, Hernes S, Slettan A, Haugen M, Ye S, Blomhoff R, Mansoor MA (2015) Effects of polymorphisms in endothelial nitric oxide synthase and folate metabolizing genes on the concentration of nitrate, folate, and plasma total homocysteine after folic acid supplementation: a double-blind crossover study. Nutrition 31:337-344

Canalle R, da Silva S, Andrade V, Scrideli CA, de Paula Queiroz RG, Tone LG (2006) Polymorphisms in the thymidylate synthase promoter and the DNA repair genes XRCC1 and XPD in a Brazilian population. Environ Mol Mutagen 47:725-732

Charasson V, Hillaire-Buys D, Solassol I, Laurand-Quancard A, Pinguet F, Le Morvan V, Robert J (2009) Involvement of gene polymorphisms of the folate pathway enzymes in gene expression and anticancer drug sensitivity using the NCI-60 panel as a model. Eur J Cancer 45:2391-2401

Clarke R, Halsey J, Lewington S, Lonn E, Armitage J et al (2010) Effects of lowering homocysteine levels with B vitamins on cardiovascular disease, cancer and cause-specific mortality:meta-analysis of 8 randomized trials involving 37485 individuals. Arch Intern Med 170:1622-1631

Daly LE, Kirke PN, Molloy A, Weir DG, Scott JM (1995) Folate levels and neural tube defects. Implications for prevention. JAMA 274:1698-1702

Devlin AM, Clarke R, Birks J, Evans JG, Halsted CH (2006) Interactions among polymorphisms in folate-metabolizing genes and serum total homocysteine concentration in a healthy elderly population. Am J Clin Nutr 83:708-713

DeVos L, Chanson A, Liu Z, Ciappio ED, Parnell LD, Mason JB, Tucker KL, Crott JW (2008) Associations between single nucleotide polymorphisms in folate uptake and metabolizing genes with blood folate, homocysteine and DNA uracil concentrations. Am J Clin Nutr 88:1149-1158

Dufficy L, Naumovski N, Ng X, Blades B, Yates Z, Travers C, Lewis P, Strum J, Veysey M, Roach PD, Lucock MD (2006) G80A reduced folate carrier SNP influences the absorption and cellular translocation of dietary folate and its association with blood pressure in an elderly population. Life Sci 79:957-966

Ebbing M, Bleie Ø, Ueland PM, Nordrehaug JE, Nilsen DW, Vollset SE, Refsum H, Pedersen EK, Nygård O (2008) Mortality and cardiovascular events in patients treated with homocysteinelowering B vitamins after coronary angiography: a randomized controlled trial. JAMA 300:795-804

Etheredge AJ, Finnell RH, Carmichael SL, Lammer EJ, Zhu H, Mitchell LE, Shaw GM (2012) Maternal and infant gene-folate interactions and the risk of neural tube defects. Am J Med Genet A $158: 2439-2446$

Finch JM, Joseph J (2010) Homocysteine, cardiovascular inflammation, and myocardial remodeling. Cardiovasc Hematol Disord Drug Targets 10:241-245 
Fredriksen $\AA$, Meyer K, Ueland PM, Vollset SE, Grotmol T, Schneede J (2007) Large-scale population-based metabolic phenotyping of thirteen genetic polymorphisms related to onecarbon metabolism. Human Mutat 28:856-865

Frosst P, Blom HJ, Milos R, Goyette P, Sheppard CA, Matthews RG, Boers GJ, den Heijer M, Kluijtmans LAJ, van den Heuve LP, Rozen R (1995) A candidate genetic risk factor for vascular disease: a common mutation in methylenetetrahydrofolate reductase. Nat Genet 10:111-113

Gemmati D, De Mattei M, Catozzi L, Della Porta M, Serino ML, Ambrosio C, Cuneo A, Friso S, Krampera M, Orioli E, Zeri G, Ongaro A (2009) DHFR 19-bp insertion/deletion polymorphism and MTHFR C677T in adult acute lymphoblastic leukaemia: is the risk reduction due to intracellular folate unbalancing. Am J Hematol 84(8):526-529

Ghishan FK, Said HM, Wilson PC, Merrell JE, Green HL (1986) Intestinal transport of zinc and folic acid: a mutual inhibitory effect. Am J Clin Nutr 43:258-262

Green R (2011) Indicators for assessing folate and vitamin B-12 status and for monitoring the efficacy of intervention strategies. Am J Clin Nutr 94(suppl):666S-672S

Hernes S, Cabo RN, Mansoor MA, Haugen M (2012) Eating patterns are associated with biomarkers in a selected population of university students and employees. J Nutr Sci 1:1-6

Homocysteine lowering trialistścollaboration (2005) Dose-dependent effects of folic acid on blood concentrations of homocysteine: a meta-analysis of the randomized trials. Am J Clin Nutr $82: 806-812$

Horie N, Aiba H, Oguro K, Hojo H, Takeishi K (1995) Functional analysis and DNA polymorphism of the tandemly repeated sequences in the $5^{\prime}$-terminal regulatory region of the human gene for thymidylate synthase. Cell Struct Funct 20(3):191-197

Kelly P, McPartlin J, Goggins M, Weir DG, Scott JM (1997) Unmetabolized folic acid in serum: acute studies in subjects consuming fortified food and supplements. Am J Clin Nutr 65:1790-1795

Manshadi SD, Ishiguro L, Sohn KJ, Medline A, Renlund R, Croxford R, Kim YI (2014) Folic acid supplementation promotes mammary tumor progression in a rat model. PLOS 9:1-10

Mansoor MA, Svardal AM, Ueland PM (1992) Determination of the in vivo redox status of cysteine, cysteinylglycine, homocysteine, and glutathione in human plasma. Anal Biochem 200:218-229

Mansoor MA, Bergmark C, Svardal AM, Lønning PE, Ueland PM (1995) Redox status and protein binding of plasma homocysteine and other aminothiols in patients with early-onset peripheral vascular disease. Homocysteine and peripheral vascular disease. Arterioscler Thromb Vasc Biol 15:232-240

Mansoor MA, Kristensen O, Hervig T, Bates CJ, Pentieva K, Vefring H, Osland A, Berge T, Drabløs PA, Hetland E, Rolfsen S (1999) Plasma total homocysteine response to oral doses of folic acid and pyridoxine hydrochloride (vitamin B6) in healthy individuals. Oral doses of vitamin B6 reduce concentrations of serum folate. Scand J Clin Lab Invest 59:139-146

Mansoor MA, Hervig T, Stakkestad JA, Drabløs PA, Apeland T, Wentzel-Larsen T, Bates CJ (2011) Serum folate is significantly correlated with plasma cysteine concentrations in healthy industry workers. Ann Nutr Metab 58:68-73

Mansoor MA, Stea TH, Schneede J, Reine A (2013) Early biochemical and hematological response to intramuscular cyanocobalamin therapy in vitamin B12-deficient patients. Ann Nutr Metab 62:347-353
Markan S, Sachdeva M, Sehrawat BS, Kumari S, Jain S, Khullar M (2007) MTHFR 677 CT/MTHFR 1298 CC genotypes are associated with increased risk of hypertension in Indians. Mol Cell Biochem 302:125-131

Mikael LG, Deng L, Paul L, Selhub J, Rozen R (2013) Moderately high intake of folic acid has a negative on mouse embryonic development. Birth Defects Res A Clin Mol Teratol 97:47-52

Milne D, Canfield W, Mahalko J, Sandstead HH (1984) Effect of oral folic acid supplements on zinc, copper, and iron absorption and excretion. Am J Clin Nutr 39:535-539

Mukherjee MD, Sandstead HH, Ratnaparkhi MV, Johnson KK, Milne DB, Stelling HP (1984) Maternal zinc, iron and folic acid protein nutriture on out-come of human pregnancy. Am J Clin Nutr 40:496-507

Nelen WLDM, Blom HJ, Thomas CMG et al (1998) Methylenetetrahydrofolate reductase polymorphism affects the change in homocysteine and folate concentrations resulting low dose folic acid supplementation in women with unexplained recurrent miscarriages. J Nutr 128:1336-1341

Pereira AC, Schettert IT, Morandini-Filho AAF, Guerra-Shinohara EM, Krieger JE (2004) Methylenetetrahydrofolate reductase (MTHFR) c677t gene variant modulates the homocysteine folate correlation in a mild folate-deficient population. Clin Chim Acta 340:99-105

Pfeiffer CM, Fazili Z, McCoy L, Zhang M, Gunter EW (2004) Determination of folate vitamers in human serum by stableisotope-dilution tandem mass spectrometry and comparison with radioassay and microbiologic assay. Clin Chem 50:423-432

Shane B (2010) Folate chemistry and metabolism. In: Bailey LB (ed) Folate in health and disease, 2nd edn. CRC Press, Boca Raton, pp 1-24

Skibola CF, Smith MT, Hubbard A, Shane B, Roberts AC, Law GR, Rollinson S, Roman E, Cartwright RA, Morgan GJ (2002) Polymorphisms in the thymidylate synthase and serine hydroxymethyltransferase genes and risk of adult acute lymphocytic leukemia. Blood 99:3786-3791

US FDA (1996) Food standards: amendment of standard of identity for enriched grain products to require addition of folic acid. United States Food and Drug Administration, Final rule 21 CFR, Parts 136, 137 and 139. Fed Regist 61:8781-8807

Van Oort FVA, Melsa-Boonstra A, Brouwer IA, Clarke R, West CE, Katan MB, Verhoef P (2003) Folic acid and reduction of plasma homocysteine concentrations in older adults: a dose-response study. Am J Clin Nutr 77:1318-1323

Yang QH, Botto LD, Gallagher M, Friedman JM, Sanders CL, Koontz D, Nikolova S, Erickson JD, Steinberg K (2008) Prevalence and effects of gene-gene and gene-nutrient interactions on serum folate and serum total homocysteine concentrations in the United States: findings from the third National Health and Nutrition Examination Survey DNA Bank ${ }^{1-4}$. Am J Clin Nutr 88:232-246

Yee SW, Gong L, Badagani I, Giacomini KM, Klein TE, Altman RB (2010) SLC19A1 pharmacogenomics summary. Pharmacogenet Genomics 20:708-715

Zappacosta B, Graziano M, Persichilli S et al (2014) 5,10methylenetetrahydrofolate reductase (MTHFR) C677T and A1298C polymorphisms: genotype frequency and association with homocysteine and folate levels in middle-southern Italian adults. Cell Biochem Funct 32:1-4

Zhao R, Diop-Bove N, Visentin M, Goldman ID (2011) Mechanisms of membrane transport of folates into cells and across epithelia. Annu Rev Nutr 31:177-201 